\title{
A novel biobased polyester plasticizer prepared from palm oil and its plasticizing effect on poly (vinyl chloride)
}

\author{
Puyou Jia ${ }^{1}$, Meng Zhang ${ }^{1,2}$, Lihong $\mathrm{Hu}^{1,2}$, Yonghong $\mathrm{Zhou}^{{ }^{*}}$ \\ ${ }^{1}$ Chinese Academy of Forest (CAF), Institute of Chemical Industry of Forest Products, Jiangsu Province, Nanjing 210042, \\ China \\ ${ }^{2}$ Chinese Academy of Forest (CAF), Institute of New Technology of Forestry, Beijing 100091, China \\ "Corresponding author: e-mail: yhzhou777@sina.com
}

\begin{abstract}
In this study, palm oil was the first time to convert into a novel polyester plasticizer for polyvinyl chloride (PVC). In the first stage, palm oil was converted into palm oil monoglyceride (POM) by alcoholysis with glycerol. Next, a novel palm oil monoglycerides based polyester plasticizer (POMP) was synthesized from POM and maleic anhydride through esterification and condensation reaction. The structure of POMP was characterized with FTIR, $1 \mathrm{H}$ NMR and GPC. Then PVC blends were prepared using POMP as a plasticizer, melting behavior, thermal property, compatibility, mechanical properties and mechanism of plasticization of PVC blends were systematically studied. Melting behavior indicated that POMP could decrease the torque and the melt viscosity of PVC blends that was conducive to process. With the content of POMP increasing from $5 \mathrm{~g}$ to $15 \mathrm{~g}$ in PVC blends, the plasticized PVC blends demonstrated better compatibility, the degradation temperature $\left(\mathrm{T}_{\mathrm{d}}\right)$ increased from $252.6^{\circ} \mathrm{C}$ to $257.0^{\circ} \mathrm{C}$, the glass transition temperature $\left(\mathrm{T}_{\mathrm{g}}\right)$ decreased from $55^{\circ} \mathrm{C}$ to $49.5^{\circ} \mathrm{C}$. Plasticization was put into effect by interaction of the electron cloud between the PVC chain and POMP molecule. This study may lead to the development of new type of PVC plasticizer based on vegetable oil.
\end{abstract}

Keywords: palm oil, polyester, plasticizer, polyvinyl chloride, blend.

\section{INTRODUCTION}

The replacement of petroleum-based raw materials by renewable resources is receiving increasing attentions in both industrial and academic setting, due to concerns regarding both economic and environmental aspects ${ }^{1-3}$. Natural vegetable oils are considered to be one of the most worthy classes of renewable sources because of the wide variety of possibilities for chemical transformations, universal availability, and low price and they are preferred by the chemical industry as alternative ${ }^{4}$. The main component of vegetable oils is triglycerides, which contain some reactive positions useful in many synthetic transformations but our research is concentrated on alcoholysis with glycerol and condensation. In this study, palm oil (PO) was as chemical for polyester plasticizer. The main fatty acid compositions of PO contain 50\% saturated, $40 \%$ monounsaturated and $10 \%$ polyunsaturated fatty acids ${ }^{2,5}$. Palm oil monoglycerides (POM) could be obtained from alcoholysis action with glycerol at $220-240^{\circ} \mathrm{C}^{6-7}$. Palm oil monoglycerides based polyester plasticizer (POMP) could be prepared by esterification and polycondensation of POM and acid anhydride.

Poly(vinyl chloride) (PVC) products are widely used in a large range of application such as window frames, wallpapers, pipes, flooring, cables, bottles, packaging and credit cards, audio records, medical tubing, blood bags and children toys ${ }^{8}$. It is also difficult to process due to its high melt viscosity caused by the rigid chain structure, resulting in a relatively high processing temperature and high screw torque9. The primary role of plasticizers is to improve the flexibility and process ability of PVC by lowing the second order transition temperature, the transition temperature $\left(T_{\mathrm{g}}\right)$. Phthalates as the main plasticizer additives of PVC have been used around the world because of excellent plasticizing effect. But phthalates may migrate from PVC products to environments when the materials contact with biological fluids. It will take potential risks to human health when they are used in food packing, automotive products ${ }^{\mathbf{1 0}}$, insect repellents and blood storage bags ${ }^{11}$. Recently, many publications reported the synthesis and possible application of PVC plasticizers derived from renewable resources such as epoxidized sunflower oil ${ }^{12}$, epoxidized safflower oil, Low-Molecular-Weight glycerol esters ${ }^{13}$, oleic acid polyester ${ }^{14}$, rice fatty $\mathrm{acid}^{15}$, and epoxidized soybean oil ${ }^{16}$.

This study synthesized a novel polyester plasticizer using renewable resources of palm oil and evaluated the properties of PVC blends plasticized with the polyester plasticizer for the first time. The properties including melting behavior, thermal property, compatibility, mechanical properties and mechanism of plasticization of PVC blends were carefully studied by evaluation of torque, TG-DTG, DMA, SEM and tensile tests respectively. It reveals that POMP could partially substitute phthalates as the environmentally friendly plasticizer of PVC. As far as we concerned, polyester plasticizer based on vegetable oil for PVC has not reported in any literature.

\section{EXPERIMENTIAL}

\section{Material}

Palm oil (PO) (Food grade, saponification value $(\mathrm{NaOH}), 0.141$, potassium values, 0.1974 , saponification value, 145) was provided by Dudu Made Ltd. (Malaysia). Dioctyl phthalate(DOP), lead oxide, calcium stearate , zinc stearate, glycerin, butyl alcohol, maleic anhydride and tetrabutyl titanate (TBT) were obtained from Nanjing Chemical Reagent Co., Ltd. Poly(vinyl chloride) (PVC) was supplied by Hanwha (South Korea) with K value 65.0 and degree of polymerization $1300 \pm 100$. All the chemicals and solvents were of synthesis grade and were used without further purification. 


\section{Synthesis of POM}

$18.4 \mathrm{~g}(0.2 \mathrm{~mol})$ of glycerol was placed in a $500 \mathrm{ml}$ three necked round-bottom flask, equipped with a mechanical stirrer, a $\mathrm{N}_{2}$ gas inlet and a downward condenser. Glycerol was then heated to about $230-240^{\circ} \mathrm{C}$ under $\mathrm{N}_{2}$ atmosphere and kept the temperature for $2 \mathrm{~h}$ until the water and glycerol mixture was distilled. Then $90 \mathrm{~g}$ (0.1 mol, assuming an average molecular weight of 900 for PO) of PO and $0.108 \mathrm{~g}$ of lead oxide $(0.1 \% \mathrm{wt}$. In relation to the total mass of reactant) was added in the mixture, and the solution was heated at $230-240^{\circ} \mathrm{C}$ for $3.5 \mathrm{~h}$ with mechanical stirring and $\mathrm{N}_{2}$ gas sparging. At the end of the time, the reaction flask was cooled in an ice and salt mixture, and the solution was rapidly cooled to room temperature. The initial excess of glycerol was separated as a lower layer and the yield of POM were approximately $50 \%$ characterized at the previous work ${ }^{6}$.

\section{Synthesis of POMP}

$14.7 \mathrm{~g}(0.15 \mathrm{~mol})$ of maleic anhydride, $3.71 \mathrm{~g}(0.5 \mathrm{~mol})$ of butyl alcohol and $0.02 \mathrm{~g}$ of $(0.03 \%$ wt. Relation the total mass of reactant) TBT were placed in the three necked round-bottom flask of POM, and the solution was slowly heated at $230-240^{\circ} \mathrm{C}$ for 6,8 and $10 \mathrm{~h}$, respectively, with mechanical stirring and $\mathrm{N}_{2}$ gas sparging. Then the condensation was allowed to proceed in a vacuum at $220^{\circ} \mathrm{C}$ for $2 \mathrm{~h}$. The total reaction time was 8,10 and $12 \mathrm{~h}$, respectively. The resulting polyesters were allowed to cool and dissolved in acetone and reprecipitated from water. The dissolution and reprecipitation were repeated three times and the polyester products dried at $60^{\circ} \mathrm{C}$ in vacuum for $24 \mathrm{~h}$ before further characterization. The idealized reaction scheme for the synthesis of POMP was depicted in the Figure 1.

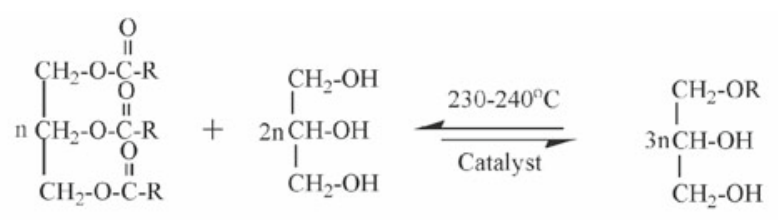

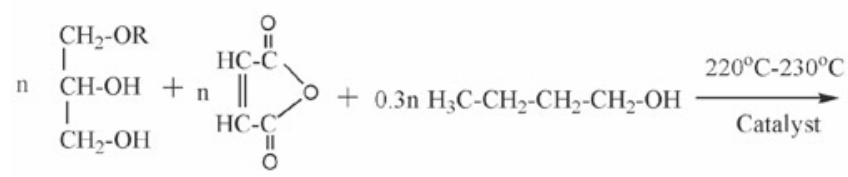

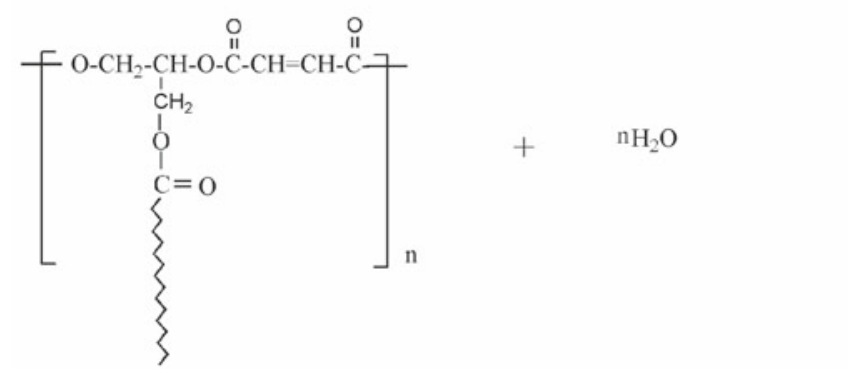

Figure 1. The idealized reaction scheme for the synthesis of POMP

\section{Preparation of Blends}

PVC blends were melting process at $165^{\circ} \mathrm{C}$ for $5 \mathrm{~min}$ at $50 \mathrm{rpm}$ using Poly Lab Torque rheometer (Hakke Instrument Crop., Germany). PVC resin was pre-treated by drying at $60^{\circ} \mathrm{C}$ for $20 \mathrm{~h}$ to eliminate possible absorbed water on the surface of particle. Formulations used for preparing plasticized PVC blends were shown in Table 1. Dumbbell-shaped samples of blends were molded on a MiniJetII Micro-injection molding machine (Hakke Instrument Crop., Germany) according GB/T 17037.1-1997(China). Mounding conditions were set at $165^{\circ} \mathrm{C}$ for $5 \mathrm{~min}$ at 550 Bar.

Table 1. Composition of PVC blend plasticized with POMP, (g)

\begin{tabular}{|l|c|c|c|c|c|}
\hline Blend & PVC [g] & $\begin{array}{c}\text { POMP-3 } \\
{[\mathrm{g}]}\end{array}$ & DOP [g] & $\begin{array}{c}\text { Calcium } \\
\text { carbonate [g] }\end{array}$ & Thermal stabilizer \\
\hline a & 100 & 5 & 35 & 10 & 2 \\
\hline b & 100 & 10 & 30 & 10 & 2 \\
\hline c & 100 & 15 & 25 & 10 & 2 \\
\hline
\end{tabular}

\section{Characterization}

\section{FT IR}

FTIR spectra of POMP were obtained on a Nicolet iS10 FT-IR (Nicolet Instrument Crop., USA). The spectra were acquired in the range of 4000 to $500 \mathrm{~cm}^{-1}$ at a resolution of $4 \mathrm{~cm}^{-1}$.

\section{GPC}

Molecular weight distribution of plasticizer based on palm oil was obtained by a Waters (USA) gel permeation chromatography (GPC) system using tetrahydrofuran (THF) as solvent. The polyester was characterized at the polycondensation time of 6,8 and $10 \mathrm{~h}$.

\section{${ }^{1}$ HNMR}

Nuclear magnetic resonance (NMR) spectra $\left({ }^{1} \mathrm{H}\right)$ of POMP were recorded operating an AV-300 instrument with tetrametnylsilane as an internal standard.

\section{Evaluation of torque}

PVC blends were melt process at $165^{\circ} \mathrm{C}$ for $4.5 \mathrm{~min}$ at 50 rpm using Poly Lab Torque rheometer(Hakke Instrument Crop., Germany). Formulations used for preparing plasticized PVC blends were shown in Table 1.

\section{TGA}

Thermal ability of PVC blends was characterized in a TG209F1 TGA thermal analysis instruments (Netzsch Instrument Crop., German) in $\mathrm{N}_{2}$ atmosphere $(50 \mathrm{~mL} /$ min) at a heating rate of $10^{\circ} \mathrm{C} / \mathrm{min}$. Approximately $5 \mathrm{mg}$ of samples were put into platinum pans and scanned from $30^{\circ} \mathrm{C}$ to $600^{\circ} \mathrm{C}$.

\section{DMA}

The dynamic mechanical analysis was performed via a DMTA Q800 (TA Instruments. USA) with gas cooling accessory to observe the $\alpha$-transitions of the PVC blends under investigation. Rectangular samples of geometry $80(\mathrm{l}) \times 10(\mathrm{w}) \times 4(\mathrm{t}) \mathrm{mm}$. The oscillatory frequency of the dynamic test was $1 \mathrm{~Hz}$; the temperature was raised at a rate of $3^{\circ} \mathrm{C} / \mathrm{min}$ in the range of $-80-100^{\circ} \mathrm{C}$.

\section{SEM}

The surfaces of PVC blends were investigated with a Hitachi 3400-1 (Hitachi, Japan) scanning electron microscope instrument, operated at $12 \mathrm{kV}$. The fracture of all surfaces was sputtered with gold to avoid electrostatic charging during examination. 


\section{Mechanical properties}

The property including tensile modulus, tensile strength, and elongation at break was determined according $\mathrm{GB} / \mathrm{T}$ 1040.1-2006 (China) under ambient conditions, using E43.104 Universal Testing Machine (MTS Instrument Crop., China). The reported values were the average of at least.

\section{RESULTS AND DISCUSSION}

\section{FTIR}

All the steps of the synthesis of POMP were followed by FTIR spectroscopy. FTIR spectra of PO, POM and POMP were compared in Figure 2. Several characteristic peaks were indicated in the spectrum of PO: methyl and methylene groups $\left(2921.29 \mathrm{~cm}^{-1}\right.$ and $\left.2852.14 \mathrm{~cm}^{-1}\right)$, and ester carbonyl groups $\left(1743.50 \mathrm{~cm}^{-1}\right)$. There were also some typical peaks in the spectrum of POM: methyl and methylene groups $\left(2916.00 \mathrm{~cm}^{-1}\right.$ and $\left.2849.93 \mathrm{~cm}^{-1}\right)$, and ester carbonyl groups $\left(1730.14 \mathrm{~cm}^{-1}\right)$. Compared to the spectrum of PO, a new peak appeared at $3306.71 \mathrm{~cm}^{-1}$, indicating hydroxyl groups on the POM structure. The peak of the ester carbonyl group shifted from $1743.50 \mathrm{~cm}^{-1}$ to $1730.14 \mathrm{~cm}^{-1}$, which suggested that the alcoholysis reaction occurred. In the spectrum of POMP, the peak at $3467.77 \mathrm{~cm}^{-1}$ was assigned to hydrogen bonded hydroxyl groups. In this study, the butyl alcohol was used as capping agent to control the molecular weight of POMP. The hydroxyl groups might come from butyl alcohol. Several characteristic peaks were indicated in the spectrum of POMP: methyl and methylene groups (2921.78 $\mathrm{cm}^{-1}$ and $\left.2852.38 \mathrm{~cm}^{-1}\right)$, and ester carbonyl groups $\left(1737.24 \mathrm{~cm}^{-1}\right)$. The peak at $1649.90 \mathrm{~cm}^{-1}$ was corresponding to the double bond $(\mathrm{C}=\mathrm{C})$ groups from maleic anhydride. All of the data indicated that POM and POMP were prepared successfully. The results were in line with the ${ }^{1} \mathrm{HNMR}$ spectrum.

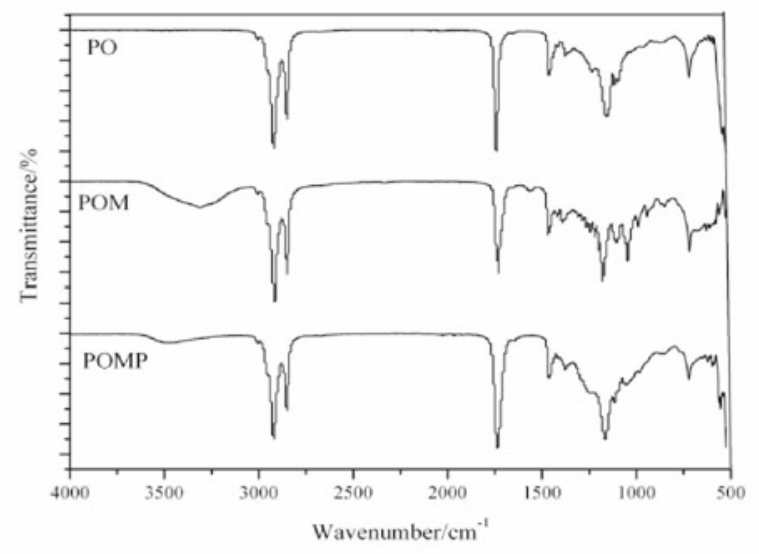

Figure 2. FTIR spectra of PO, POM and POMP

\section{GPC}

The molecular weight distribution of products was characterized using GPC. The results were presented in Table 2, the molar mass increased obviously with the extension of the reaction time, the $M_{n}$ increased from 1827 to 3101 when the reaction time was $12 \mathrm{~h}$. The polydispersity was around 1.49-2.10, which indicated that the molar mass of POMP presented a narrow distribution. The slight shifting of polydispersity of POMP was mainly caused by the shifting vacuum degree, which was difficult to be controlled at the same value in different operation of the lab experiment. The results of GPC were reasonable combining with the FTIR and ${ }^{1} \mathrm{H}$ NMR spectra.

\section{${ }^{1} \mathbf{H}$ NMR}

The ${ }^{1} \mathrm{H}$ NMR spectrum of POMP was described in the Figure 3. From the Figure 3, the methyl protons were at $\delta=0.85 \mathrm{ppm}$ (peak 1$)$, the fatty acid protons [ $\left.\left(\mathrm{CH}_{2}\right)-\mathrm{CO}-\right]$ (peak 5) were at $\delta=2.4 \mathrm{ppm}$, and the methylene protons of glycerol were in the range of $\delta=4.1-4.4$ ppm (peak 7). These peaks are always taken as reference, because the intensity of the peaks should not be altered throughout the reaction ${ }^{\mathbf{1 6}}$. The peak at 5.4 ppm (peak 8) is corresponding to the double bond protons $(-\mathrm{CH}=\mathrm{CH}-)$ of maleic anhydride. The peak at 1.6 ppm (peak 3) and 2.0 ppm (peak 4) were corresponding the methylene groups on the backbone of POM part from POMP. The results were consistent with the FTIR spectrum.

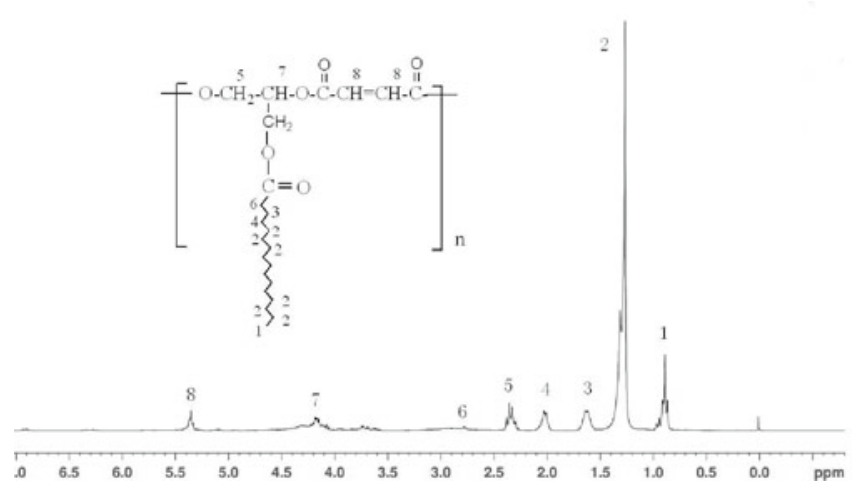

Fig 3. ${ }^{1} \mathrm{H}$ NMR spectra of POMP

\section{Evaluation of torque}

Melting behavior of PVC blends was investigated by torque variation during blends mixing in relation to the plasticizer content. Processing data were collected during mixing in the Haake chamber. There are three important variables in this process which are the chamber temperature, rotating speed and rotor torque. The chamber temperature and rotating speed was fixed, and the torque data were collected and related directly to the melt viscosity, the material resistance to flow. During processing, the melt temperature remained approximately constant. The torque rheological curve of PVC blends and the figure of torque values relative to the proportion of plasticizer in blends were shown in Figure 4 and

Table 2. The GPC results of POMP

\begin{tabular}{|l|c|c|c|c|}
\hline POMP & Polycondensation time $[\mathrm{h}]$ & $\mathrm{M}_{\mathrm{n}}[\mathrm{g} / \mathrm{mol}]$ & $\mathrm{M}_{\mathrm{w}}[\mathrm{g} / \mathrm{mol}]$ & $\mathrm{M}_{\mathrm{z}}[\mathrm{g} / \mathrm{mol}]$ \\
\hline POMP-1 & 6 & 1827 & 2103 & 3612 \\
\hline POMP-2 & 8 & 2423 & 3214 & 4.49 \\
\hline POMP-3 & 10 & 3101 & 3716 & 4547 \\
\hline
\end{tabular}




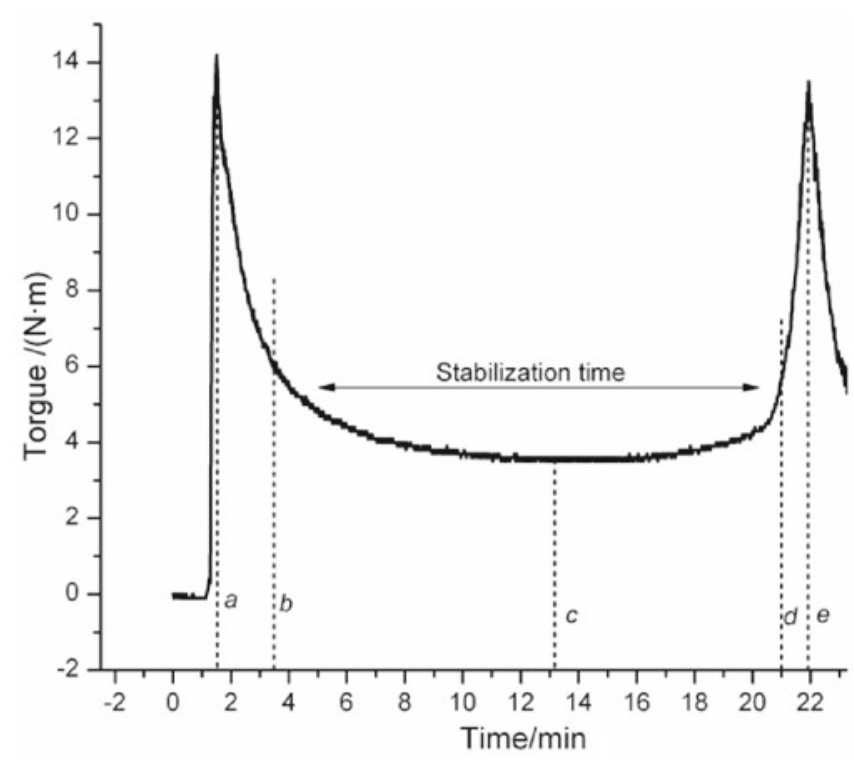

Figure 4. Torque rheological curve of PVC blends

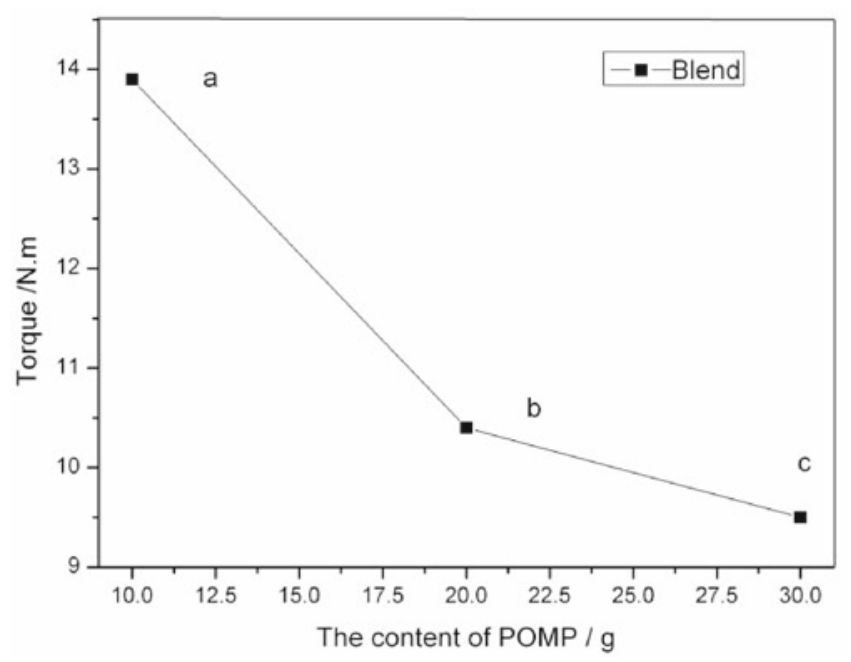

Figure 5. Torque variation during blends mixing in relation to the plasticizer content

Figure 5. As can be seen from the Fig. 4, the point a is the feeding peak which indicates the maximum torque, the point $\mathrm{b}, \mathrm{c}, \mathrm{d}$ and $\mathrm{e}$ is stable torque, minimum torque, starting point of degradation and end of degradation, respectively. PVC material should be taken from torque rheometer and the thermoplastic processing should be stopped at the point of stable torque. PVC will be started degrading after the time. From the Figure 5, with the increasing of POMP, the torque of PVC blends decreased from $13.8 \mathrm{~N} \cdot \mathrm{m}$ (a) to $9.5 \mathrm{~N} \cdot \mathrm{m}$ (c), which corresponds to $31.16 \%$ decrement. The torque decrement could decrease the melt viscosity and would improve thermoplastic processing of PVC blends.

\section{TGA}

The thermal stability of PVC blends was characterized with thermogravimetric analysis and differential thermal analysis. The TG curves and the DTG curves

Table 3. The TGA and DTG results of PVC blends

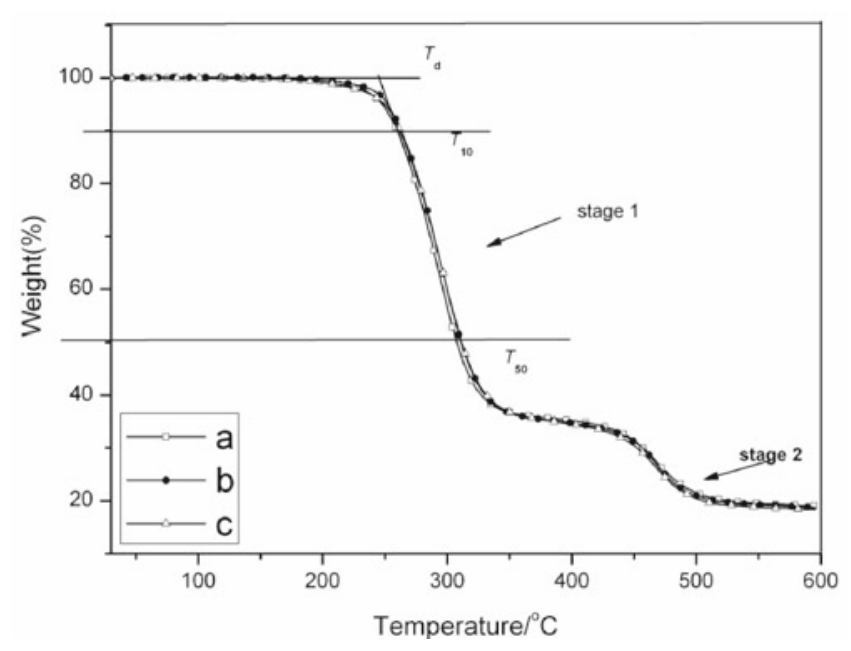

Figure 6. TG curves of PVC blends

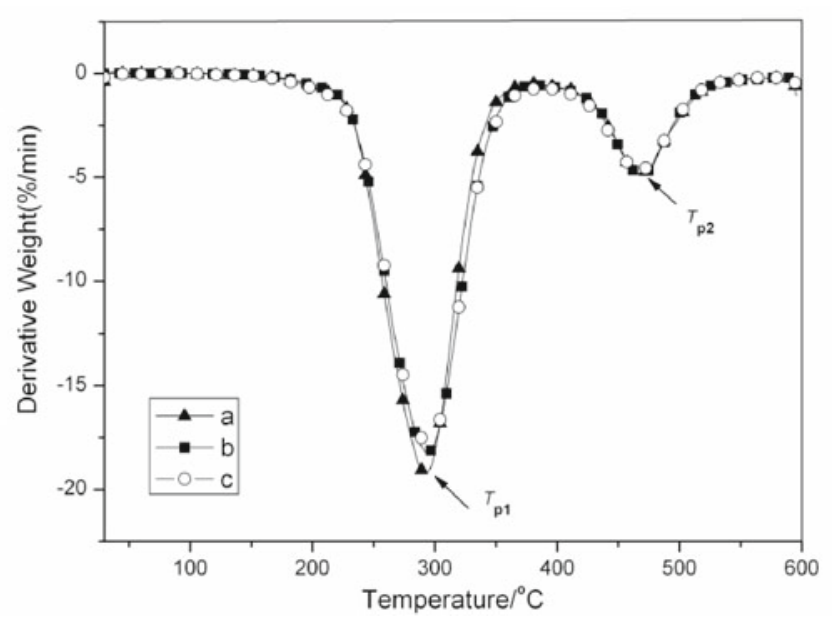

Figure 7. DTG curves of PVC blends

were depicted in Figure 6 and Figure 7, respectively. The TG curves showed a two-stage thermal degradation process above $200^{\circ} \mathrm{C}$. The first stage degradation at around $200-450^{\circ} \mathrm{C}$ could be attributed to the formation and stoichiometric elimination of $\mathrm{HCl}$. The second stage at above $450^{\circ} \mathrm{C}$ is attributed to cross linking containing $\mathrm{C}=\mathrm{C}$ bonds and degradation of an inert filler such as thermal stabilizers. Thermal degradation of polyenes involves cyclization and splitting of chains ${ }^{12,21}$. DTG curves of PVC blends showed two degradation peaks at around $290^{\circ} \mathrm{C}$ and $460^{\circ} \mathrm{C}$. The two mass peaks are corresponding to two thermal degradation stages.

Table 3 summarized the parameters of TGA and DTG, including decomposition temperature $\left(T_{\mathrm{d}}\right), 10 \%$ and $50 \%$ weight-loss temperature $\left(T_{10}\right.$ and $\left.T_{50}\right)$ and temperature at the maximum weight-loss temperature rate $\left(T_{\mathrm{P}}\right)$. As the increase in content of POMP, $T_{\mathrm{d}}$ increased from $254.6^{\circ} \mathrm{C}$ to $257.0^{\circ} \mathrm{C}, T_{10}, T_{50}$ and $T_{\mathrm{P} 1}$ increased obviously. The results indicated that POMP could improve the thermal stability of PVC blends.

\section{DMA}

DMA technology was employed to investigate the glass transition temperature ( $\mathrm{Tg}$ ) of the PVC blends. The results were shown in Figure 8 and the Table 3.

\begin{tabular}{|l|c|c|c|c|c|c|c|}
\hline Samples & $T_{\mathrm{d}}\left[{ }^{\circ} \mathrm{C}\right]$ & $T_{10}\left[{ }^{\circ} \mathrm{C}\right]$ & $T_{50}\left[{ }^{\circ} \mathrm{C}\right]$ & $T_{\mathrm{P} 1}\left[{ }^{\circ} \mathrm{C}\right]$ & $T_{\mathrm{P} 2}\left[{ }^{\circ} \mathrm{C}\right]$ & $T_{\mathrm{g}}\left[{ }^{\circ} \mathrm{C}\right]$ & Residue $[\%]$ \\
\hline a & 252.6 & 258.5 & 311.6 & 292.6 & 469.3 & 55 & 19.0 \\
\hline $\mathrm{b}$ & 255.3 & 261.8 & 315.3 & 293.7 & 466.3 & 53.2 & 18.27 \\
\hline $\mathrm{c}$ & 257.0 & 265.2 & 318.0 & 294.0 & 469.9 & 49.5 & 18.71 \\
\hline
\end{tabular}


There was only a tan $\delta$ peak could be observed in every DMA curve, which indicated that compatibility of the PVC and POMP was excellent, and the DMA data indicated that the $\tan \delta$ peak shift to lower temperature with increasing content of POMP. From the Table 3, the $\mathrm{Tg}$ decreased from $55^{\circ} \mathrm{C}$ to $49.5^{\circ} \mathrm{C}$ with the content of POMP increased from $5 \mathrm{~g}$ to $15 \mathrm{~g}$ in PVC blend. The decrease of $\mathrm{Tg}$ indicated that the chain mobility of PVC increased. The change of $\mathrm{T}_{\mathrm{g}}$ of $\mathrm{PVC}$ is in agreement with the common rule the plasticizer can decrease the $\mathrm{T}_{\mathrm{g}}$ of PVC. It could be demonstrated that POMP could interact with PVC molecular and increase the mobility of PVC chain segment.

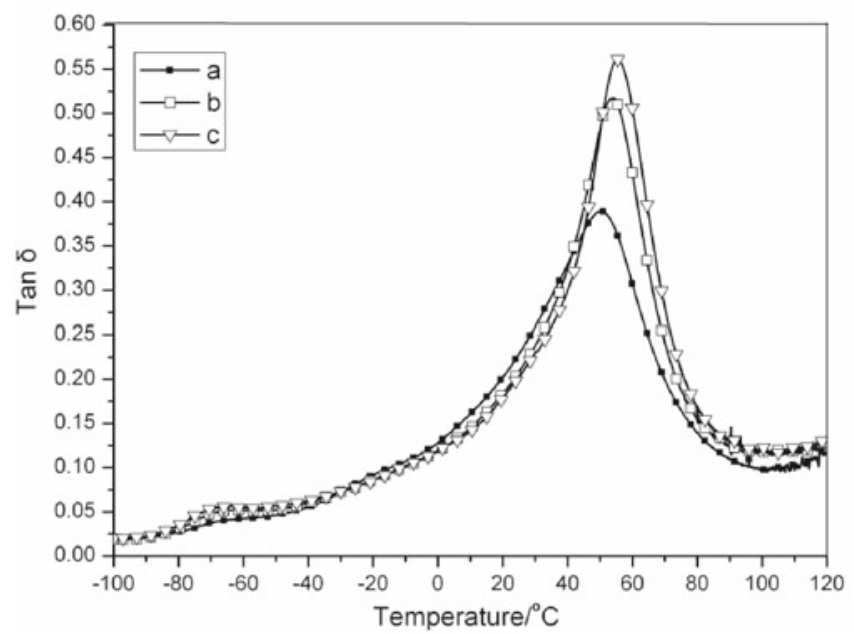

Figure 8. DMA curves of PVC blends

\section{SEM}

The unique nature of PVC is able to accommodate a large number of plasticizer. Plasticizing process was completed only when the polar groups of the PVC chain were shielded by plasticizer molecule. Interaction of the electron cloud between the PVC chain and POMP molecule was depicted in Figure 9. From the Figure 9, there are many connection points between PVC chain and POMP molecule could be observed. The reason of the torque and melt viscosity decreased in the melting process could be explained by the contact structure, because the contact structure increased the mobility of PVC chain. Another important characteristic of plasticizer is compatibility. A good compatibility could reduce plasticizing temperature, restrain the release of plasticizer from the products, improve the flexibility of products and extend the service life of products. The

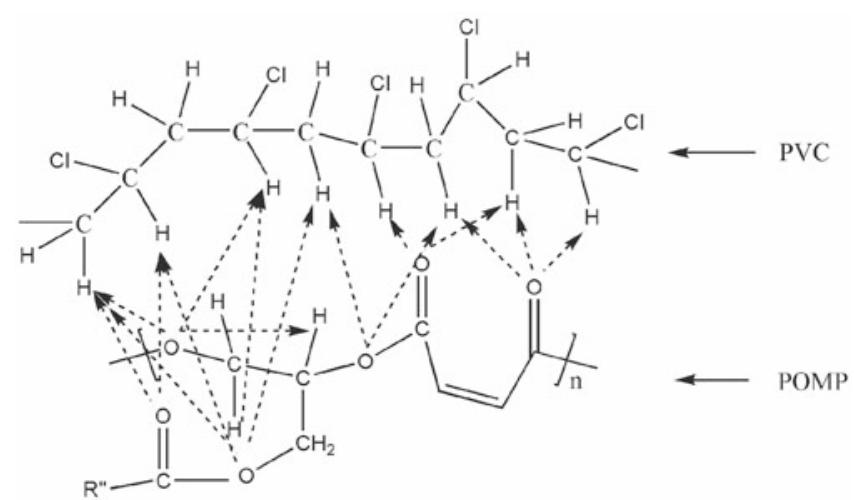

Figure 9. Structure diagram of the connections between PVC segment and POMP cross section of PVC blends was depicted with SEM. The cross section of $a, b$ and $c$ sample was showed in Figure 10, Figure 11 and Figure 12, respectively. From the Figure 10, a large number of particles could be observed on the cross section of sample a, the particles appearing on the cross section properly the result of some plasticizer excess that was scattered outside the PVC matrix. It caused the eventual migration of plasticizer out of PVC during processing and using. PVC plasticized with POMP showed few particles in Figure 12. The plasticizer dispersed in the PVC matrix uniformly and surrounded intimately with PVC continuous phase, and there is

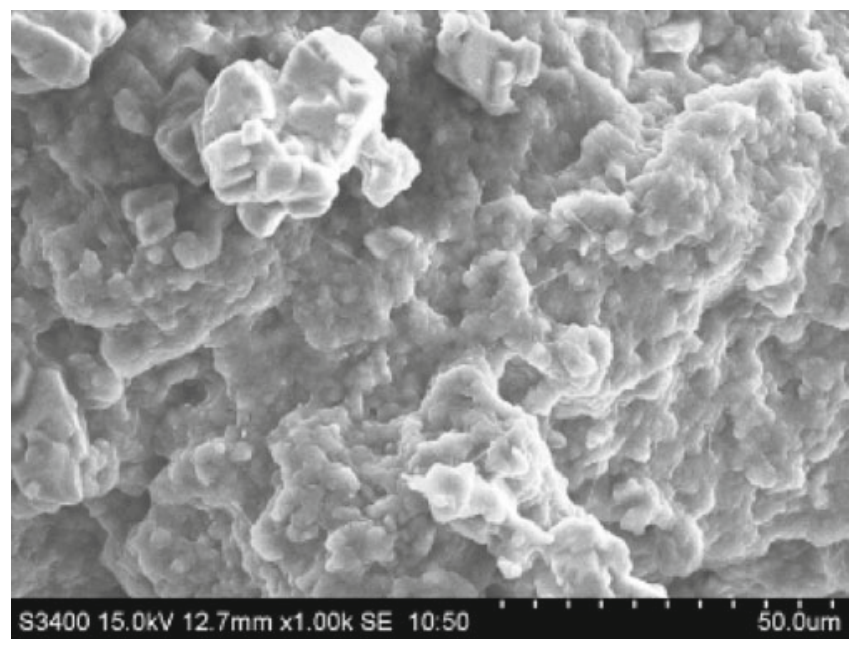

Figure 10. SEM micrographs of surfaces of PVC blend a

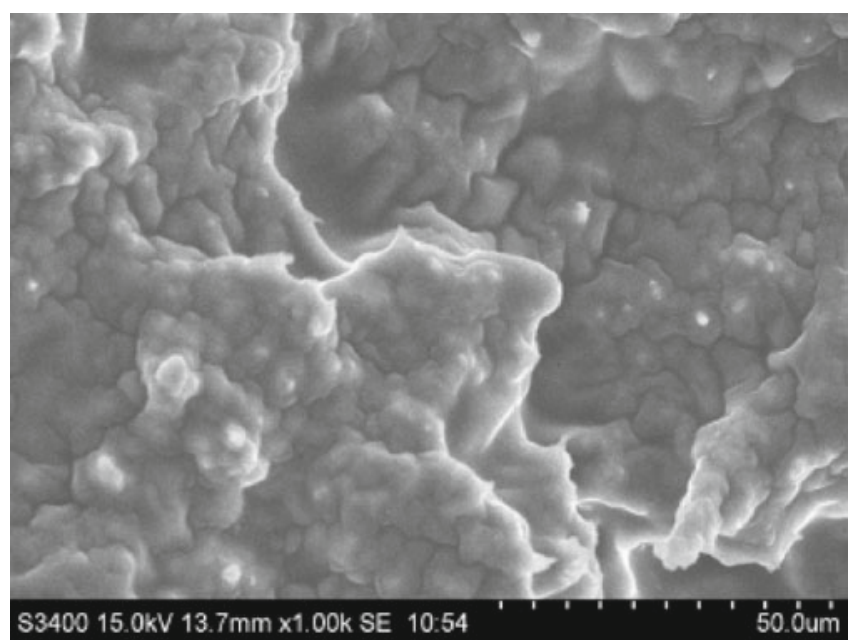

Figure 11. SEM micrographs of surfaces of PVC blend $b$

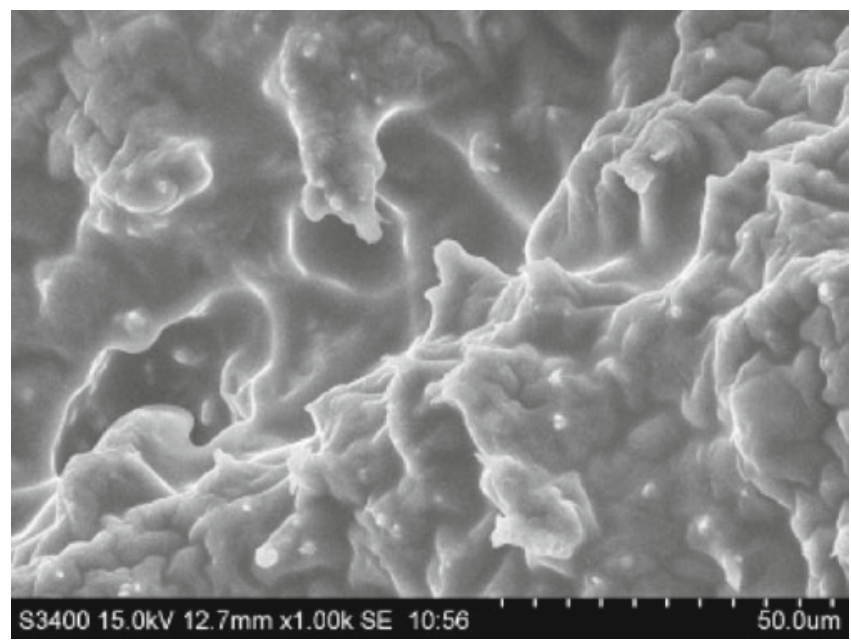

Figure 12. SEM micrographs of surfaces of PVC blend $\mathrm{c}$ 
a few particles between them to be observed. So there is good interracial adhesion between POMP and PVC.

\section{Mechanical properties}

The efficiency of plasticizers could be evaluated by the tensile strength along and elongation at break. Table 4 summarized the values of the mechanical properties of PVC blends. A significant influence of the addition of different content of POMP for PVC blends could be observed. With the addition of POMP and reduction of DOP in the PVC blends, the tensile strength decreased from 12.6 MPa to $6.1 \mathrm{MPa}$, and the elongation at break decreased from $210.81 \%$ to $60.96 \%$. It is not accordance with the common rule that the plasticizer can increase the elongation at break and decrease the tensile strength Modulus of elasticity. It could indicate that the POMP has plasticization in PVC but the plasticizing efficiency is lower than DOP. However, the appropriate PVC products could be prepared by modifying the composition of PVC blends.

Table 4. The chemical composition of the solid phase obtained during conversion when the molar ratio of $\mathrm{KCl}$ and $\mathrm{NH}_{4} \mathrm{H}_{2} \mathrm{PO}_{4}$ is equal 0.8:0.2

\begin{tabular}{|l|c|c|c|}
\hline Blend & Tensile strength [MPa] & Elongation at break [\%] & Tensile modulus [MPa] \\
\hline a & 12.6 & 210.81 & 110.16 \\
\hline b & 10.3 & 140.42 & 40.26 \\
\hline c & 6.1 & 60.96 & 22.56 \\
\hline
\end{tabular}

\section{CONCLUSION}

In this wok, a vegetable oil based polyester plasticizer POMP was first synthesized. The molar mass of POMP increased obviously from 1827 to 3101 when the reaction time was $12 \mathrm{~h}$. Then PVC blends were prepared using POMP and as plasticizer, with the content of POMP increasing from $5 \mathrm{~g}$ to $15 \mathrm{~g}$ in PVC blend, the plasticized PVC blends demonstrated that the degradation temperature $\left(\mathrm{T}_{\mathrm{d}}\right)$ increased from $252.6^{\circ} \mathrm{C}$ to $257.0^{\circ} \mathrm{C}$ and the glass transition temperature decreased from $55^{\circ} \mathrm{C}$ to $49.5^{\circ} \mathrm{C}$. Plasticization was put into effect by interaction of the electron cloud between the PVC chain and POMP molecule. There are many connection points of electron cloud between the PVC chain and POMP molecule, the contact structure increased the mobility of PVC chain, which caused the decrement of glass transaction temperature and decreased the torque and melt viscosity in the melting process. The cross section of $\mathrm{PVC}$ plasticized with POMP showed homogeneous and smooth, which indicated that there got a better compatibility between POMP and PVC. It could reduce plasticizing temperature, restrain the release of plasticizer from the products, improve the flexibility of products and extend the service life of products. The enhancement of plasticization will expand the application range of PVC plasticized with POMP materials.

\section{ACKNOWLEDGEMENTS}

This work was supported by National 12th Five-year Science and Technology Support Plan (Grant No. 2015BAD15B08); Jiangsu Province Natural Science Foundation of China (Grant No. BK20141074).

\section{LITERATURE CITED}

1. Bozell, J.J., Moens, L. Elliott, D.C., Wang, Y., Neuenscwander, G.G., Fitzpatrick, S.W., Bilski, R.J. \& Jarnefeld, J.L. (2000). Production of levulinic acid and use as a platform chemical for derived products. Resour. Conserv. Recy. 28, 227-239. DOI: S0921-3449(99)00047-6.

2. Bozell, J.J. (2008). Feedstocks for the Future - Biorefinery Production of Chemicals from Renewable. Carbon Clean: Soil, Air, Water, 36(8), 641-647. DOI:10.1002/clen.200800100.

3. Williams, C.K. \& Hillmyer, M.A. (2008). Polymers from Renewable Resources: A Perspective for a Special Issue of Polymer Reviews. Polym. Rev., 48, 1-10. DOI: 10.1080/15583720701834133.

4. Ronda, J.C., Lligadas, G., Galia `, M. \& Ca’diz, V. (2011). Vegetable oils as platform chemicals for polymer synthesis. Eur. J. Lipid Sci. Technol., 113, 46-58. DOI: 10.1002/ejlt.201000103.

5. Edem, D.O. (2002). Palm oil: Biochemical, physiological, nutritional, hematological, and toxicological aspects: A review. Plant Foods Hum. Nutr., 57, 319-341.

6. Zhang, L.Q., Zhang, M., Hu, L.H. \& Zhou, Y.H. (2014). Synthesis of rigid polyurethane foams with castor oil-based flame retardant polyols. Ind. Crop Prod., 52, 380-388. http:// dx.doi.org/10.1016/j.indcrop.2013.10.043

7. Liu, C.G., Li, J. Lei, W. \& Zhou, Y.H. (2014). Development of biobased unsaturated polyester resin containing highly functionalized castor oil. Ind. Crop Prod. 52, 329-337. http:// dx.doi.org/10.1016/j.indcrop.2013.11.010

8. Saeki, Y. \& Emura, T. (2002). Technical progresses for PVC production. Prog. Polym. Sci. 27, 2055-2131. http:// www. elsevier.com/locate/ppolysci.

9. Liang, G.G., Cook, W.D., Tcharkhtchi, A., Sautereau, H. (2011). Epoxy as a reactive plasticizer for improving polycarbonate processibility. Eur. Polym. J. 47, 1578-1588. DOI: 10.1016/j.eurpolymj.2011.05.005.

10. Xu, Q., Yin, X., Wang, M., Wang, H., Zhang, N. \& Shen. (2010). Analysis of phthalate migration from plastic containers to packaged cooking oil and mineral water.J. Agr. Food Chem. 58, 11311-11317. DOI: 10.1021/jf102821h.

11. Ioannis, S., Arvanitoyannis, K. \& Kotsanopoulos, V. (2012). Smoking of fish and feafood: History, Methods and Effects on Physical, Nutritional and Microbiological Properties. Food Bioprocess Tech. 5, 831-853. DOI: 10.1007/s11947011-0690-8.

12. Lardjane, N., Belhaneche-Bensemra, N. \& Massardier, V. (2013). Migration of new bio-based additives from rigid and plasticized PVC stabilized with epoxidized sunflower oil in soil. J. Polym. Res. 20, 209-219. DOI: 10.1007/s10965-013-0209-2.

13. Sander, M.M., Nicolau, A., Guzatto, R. \& Samios, D. (2012). Plasticiser effect of oleic acid polyester on polyethylene and polypropylene. Polym. Test. 31, 1077-1082. http://dx.doi. org/10.1016/j.polymertesting.2012.08.006

14. Silva, M.A.D., Vieira, M.G.A., Maçumoto, A.C.G. \& Beppu, M.M. (2011). Polyvinylchloride (PVC) and natural rubber films plasticized with a natural polymeric plasticizer obtained through polyesterification of rice fatty acid. Polym. Test, 30, 478-484. DOI: 10.1016/j.polymertesting.2011.03.008.

15. Bueno-Ferrer, C., Garrigós, M.C. \& Jiménez, A. (2012). Characterization and thermal stability of poly(vinyl chloride) plasticized with epoxidized soybean oil for food packaging. Polymer Degrad. Stab., 95, 2207-2212. DOI: 10.1016/j.polymdegradstab.2010.01.027.

16. Karmalm, P., Hjertberg, T., Jansson, A. \& Dahl, R. (2009). Thermal stability of poly(vinyl chloride) with epoxidised soybean oil as primary. plasticizerPolymer Degrad. Stab., 94, 2275-2281. DOI: 10.1016/j.polymdegradstab.2009.07.019. 